\title{
Inter-Regional Spillover of Carbon Emissions and Employment in China: Is It Positive or Negative?
}

\author{
Wenbin Shao ${ }^{1,2}$, Fangyi Li ${ }^{1,2, *}$, Zhaoyang Ye ${ }^{1,2}$, Zhipeng Tang ${ }^{3, *}$, Wu Xie ${ }^{1,2}$, Yu Bai ${ }^{1,2}$ \\ and Shanlin Yang ${ }^{1,2}$ \\ 1 School of Management, Hefei University of Technology, Hefei 230009, China \\ 2 Research Center of Industrial Transfer and Innovation Development, Hefei University of Technology, \\ Hefei 230009, China \\ 3 Institute of Geographic Sciences and Natural Resources Research, Chinese Academy of Sciences, \\ Beijing 100101, China \\ * Correspondences: fyli@hfut.edu.cn (F.L.); tangzhipeng@amss.ac.cn (Z.T.); Tel.: +86-551-6291-9155 (F.L.); \\ Tel.: +86-10-6488-9529 (Z.T.)
}

Received: 15 May 2019; Accepted: 26 June 2019; Published: 1 July 2019

\begin{abstract}
International and inter-regional trade in China has been promoted, the economic and environmental impacts of which are significant in regional development. In this paper, we analyzed the evolution of inter-regional spillover of carbon emissions and employment in China from 2007 to 2012 with structural decomposition method and multi-regional input-output tables. The index of carbon emission per employee (ICE) is designed and compared to indicate positive or negative spillover effects. We find that carbon emissions grow much more rapidly in interior regions than in coastal regions, due to spillover effects and own influences. Spillover effects rarely reduce the ICE of destination regions, but the own influences can decrease it in most regions. Although spillover may contribute to economic development in most regions, it is hardly a driver of efficiency improvement in destination regions. Based on these empirical findings, we put forward specific suggestions to improve the positive spillover effects on different kinds of regions.
\end{abstract}

Keywords: multi-regional input-output model; spillover effects; carbon emission; employment; trade evolution

\section{Introduction}

As the largest developing country in the world, China is a country with large spatial disparities, not only in climate, geography and resource endowment but also in economic development, industrial structure and household consumption. There is a growing need to explore the inter-regional cooperation and interactions because of their profound effects on regional economic development and carbon emissions. Among them, the inter-regional spillover is of great significance. It is worth noting that spillover may have positive and negative effects on regions. On the one hand, growth of value added and employment caused by trade can be regarded as positive spillover effects. On the other hand, the effects on environment may be negative in some regions, such as carbon emissions growth and environmental degradation. As the world's top carbon emitter [1], China has committed to reducing its carbon intensity and controlling gross emissions over the next decade and has allocated emissions reduction goals to regions. Therefore, not only the positive spillover effects, but also the effects on regional carbon emissions require more attention. Combination and compare of the two sides will shed light on the inter-regional interactions and contribute to regional emission control. In this paper, we attempted to investigate the positive and negative spillover effects of inter-regional trade evolution on individual regions of China, among which employment and carbon emission were selected as representative indices. 
Virtual $\mathrm{CO}_{2}$ and pollutants embodied in trade or consumption have attracted much attention in the recent literature [2-6]. Studies concerning the determinants of China's $\mathrm{CO}_{2}$ emissions growth have used various approaches and databases, among which Structural Decomposition Analysis (or SDA), based on input-output tables, has been frequently used [7-9]. Since the input-output tables fall into two categories of single region input-output (or SRIO) and multi-regional input-output (or MRIO) tables, SDA can also be divided into two types. In addition, empirical analysis has been adopted in a wealth of research from these two perspectives. Some scholars have used SRIO methods to study the drivers of carbon emissions changes [10-12] and employment growth [13]. Compared with SRIO-based research, MRIO-based research has become increasingly popular in studies of environmental and resource issues due to its international or inter-regional trade matrices. The SRIO model can only reveal a single closed flow situation, and there are great differences among the various provinces in China. The MRIO model can be used to analyze the internal and external connections of provinces, which is of great significance for studying the inter-regional interactions and spillover effects. MRIO-based SDA was used to investigate the driving forces from local and other regions or countries [14-19]. In the most recent literature, it was found that China's carbon emissions flow patterns have changed greatly in both domestic and foreign trade since the financial crisis [20], and energy intensity was one of the main drivers of carbon emission reduction in China's regions [21].

Since employment plays an important role in policy making, it is regarded as representative of trade benefits. Some scholars have also used MRIO to study employment issues [22]. Through the composition analysis of the decisive factors of employment growth in many countries, it was found that the change in structure and final demand played important roles in employment changes [23]. A majority of the existing research has studied carbon emissions and employment separately, but some researchers have attempted to connect them. Associating SRIO with MRIO, Zhao et al. [24] analyzed the impact of the regional shifting of the two on the trade partnerships between China and other countries in the Asia-Pacific region, focusing on employment as economic benefits and carbon emission as environment costs. Tang et al. [25] pointed out that it would be difficult for China to maintain the cost balance caused by unemployment if it reduces its exports of untapped energy, according to a trade-off study of China's untapped energy exports and employment. Generally, countries and regions are required to consider factors such as employment and environment when formulating trade policies [26], which is also why comprehensive and trade-off analysis is much more valuable for policy making than other approaches.

In some of the literature, spatial pattern of emission with its evolution was analyzed in detail $[27,28]$. Among the studies, spillover effect was defined as the interaction between countries or regions $[17,29,30]$. For a spatial analysis on spillover effects, MRIO-based SDA has been used to quantify the effects and identify factors across regions. For example, an alternative spatial structural decomposition method was employed to elucidate the importance of domestic regional heterogeneity and inter-regional spillover effects on China's regional $\mathrm{CO}_{2}$ emissions growth [30]. Thus, spillover effect analysis can be used to indicate a region's impact on other regions, explore the extent of the impact, and ultimately attain the approaches. So far, existing research has generally considered only one kind of spillover effect. For example, studies focusing on spillover effects on regional carbon emissions or employment, can provide policy references for the global optimization of emissions reduction or employment improvement. However, individual effect analysis is not sufficient to provide realistic suggestions. For developing countries such as China, control of greenhouse gases (GHG) is not the only target of central governments; there are many other targets as significant as GHG control, such as boosting economic development, ensuring social stability, and preventing environmental degradation. Therefore, policies enacted unilaterally depending on one target are unsatisfactory. Comprehensive studies including perspectives from the economy, society, environment and technology are much more convincing when aiding decision-making. Moreover, the diversity and complications of spillover effects of trade evolution should be noticed, as carbon emission, virtual water, employment, economic interest and social cost can be considered. There are a large number of trade-off and co-benefit questions 
to be answered if we investigate spillover effects from multi-perspectives. For example, spillover effect need to be intensified if it can help to decrease carbon emission and promote economic development at the same time.

This paper aims to provide reasonable suggestions for carbon emission reduction and employment promotion for different regions, based on quantification of the inter-regional spillover effects on carbon emissions and employment. Regional employment is selected elaborately as an indicator of spillover effect here because of its significance and available data. On the one side, employment stabilization is one of the most important development targets of central and provincial governments. On the other side, spillover effects on employment are beneficial to regional coordinated development, especially to underdeveloped regions which are eager to undertake industrial transfer.

The contribution of the study is as follows. Firstly, it transforms the spillover effect from a single effect to multiple effects, with the positive and negative effects compared and discussed. Secondly, a cross-sectional analysis of regions and drivers has been carried out for regional carbon emissions and employment amount changes, so as to reveal the complex relationships of mutual spillover effects on different regions. Finally, driving forces of spillover effects are closely integrated with policies, and specific policy suggestions are put forward with the purpose of promoting positive spillover effects. The remainder of this article is organized as follows. The second part introduces the methodology and data sources. The third section presents the results and discussion. The fourth part mainly provides conclusions at the end.

\section{Methodology and Data Sources}

\subsection{Methodology}

\subsubsection{MRIO-based SDA}

As is shown in $S 1$, the change in regional carbon emissions $\Delta G$ is decomposed into seven parts by different factors: carbon intensity effect $\Delta \hat{C}$, production technology effect $\Delta B$, final demand scale effect $\Delta s$, export scale effect $\Delta f^{E}$, final demand preference $\Delta P$, export preference $\Delta P^{E}$, and final demand structure $\Delta D$.

At the same time, the change in regional employment amount $\Delta W$ can similarly be decomposed into seven parts: employment intensity effect $\Delta \hat{L}$, production technology effect $\Delta B L$, final demand scale effect $\Delta f L$, export scale effect $\Delta f L^{E}$, final demand preference effect $\Delta P L$, export preference effect $\triangle P L^{E}$ and final demand structure effect $\Delta D L$.

\subsubsection{Spillover Effects Assessment}

The change in carbon emissions or employment of a region can be divided into two parts. One is attributed to the region itself and the other is attributed to inter-regional spillover effects. In the results of decomposition analysis and their division into intra-regional effects (or own influence) and spillover effects. Since intensity effect changes are not linked to regional trade, $\Delta \hat{C}$ as the carbon intensity effect and $\Delta \hat{L}$ as the employment intensity effect do not involve spillover effects. The other driving forces' effects on regions contain own influences and spillover effects both [30].

To further explore spillover effects, we construct a ratio indicator to measure the united spillover effects on carbon emissions and employment. First, there is the benchmark of carbon emissions divided by employment amount in each region in 2007, as shown in Equation (1).

$$
I C E_{t 0}^{s}=G_{t 0}^{s} / W_{t 0}^{s}
$$

where $I C E_{t 0}^{s}$ is the index of carbon emission per employee at the initial time in region s. $G_{t 0}^{s}$ is carbon emission of region $\mathrm{s}$ in the year $t_{0}$, and $W_{t 0}^{s}$ is total employment of region $\mathrm{s}$ in the year $t_{0}$. For further unitization, the quotient of carbon emissions growth and employment growth by spillover effect from region $\mathrm{r}$ to region $\mathrm{s}$ in the studying period is defined as $I C E_{q}^{r \rightarrow s}$, where $q$ is the type of driving force. 
Then we can obtain $h_{q}^{r \rightarrow s}$, as shown in Equation (2), which is defined as the spillover effect on ICE from region $\mathrm{r}$ to region $\mathrm{s}$, while $r \rightarrow s$ indicates the direction of the spillover effect.

$$
h_{q}^{r \rightarrow s}=\frac{I C E_{q}^{r \rightarrow s}}{I C E_{t 0}^{s}}
$$

If $h_{q}^{r \rightarrow s}$ is greater than 0 and less than 1 , the spillover effect on $I C E^{s}$ is defined as a positive one, or if $h_{q}^{r \rightarrow s}$ is greater than 1 , the spillover effect is negative. If $h_{q}^{r \rightarrow s}$ is less than 0 , it can be divided into two cases: carbon emission grows but employment decreases, and the spillover effect is negative; otherwise, it is positive.

Among the bilateral spillover effects on the index of carbon emission per employee, we mainly focus on the results of positive spillover effects. Moreover, we expect to construct positive impact indices (or PIIs) to reflect the positive contributions of regions to others or the positive effects received from others. Such indices are calculated as percentages, shown in Equations (3) and (4).

The PII of the spillover effect of region $s$ on other regions can be calculated as follows.

$$
P I I^{S \rightarrow \text { thers }}=\sum_{r=1,1 \neq s}^{n} \text { gdp positivers } / g d p^{\text {all }}
$$

The PII of the spillover effect of other regions on region $s$ can be calculated as follows.

$$
P I I^{\text {others } \rightarrow s}=\sum_{r=1, r \neq s}^{n} \text { Sd } \text { posithers } \rightarrow s_{\text {posive }} / g d p^{\text {all }}
$$

In the equations, $\sum_{r=1, r \neq s}^{n} g d p_{\text {positive }}^{s \rightarrow \text { ind }}$ indicates the sum of the gross domestic product (GDP) of the regions, which can receive positive spillover effect from region $s$, while $\sum_{r=1, r \neq s}^{n} g d p_{\text {positive }}^{\text {others }}$ denotes the sum of the GDPs of regions, from which region s can receive positive spillover effects, and $g d p^{a l l}$ represents the GDPs of all of the regions.

\subsection{Data Sources}

The main sources of data in this paper are from China's MRIO tables of 2007 and 2012. These two tables were both jointly prepared by the Institute of Geographic Sciences and Natural Resources Research of the Chinese Academy of Sciences and the National Bureau of Statistics of China. The tables of 2007 [31] and 2012 [32] were officially published in Chinese. The key method to establish the MRIO is introduced in the literature [33].

The data on carbon emissions comes from the China Emission Accounts and Datasets [34], and the data on employment amount comes from the China Population and Employment Statistics Yearbook 2008 and 2013 [35,36]. The employment amount is the number of formal employment in urban regions, excluding urban private and individual enterprises. The value added of each sector in each region in 2012 is provided by China Statistical Yearbook 2013 [37]. This article focuses on 30 provinces and municipalities of mainland China, excluding Tibet, Taiwan, Hong Kong and Macau due to lack of data. Besides, 30 provinces and municipalities are merged into eight regions based on the economic and geographic locations according to the Development and Reform Commission of the State Council [38], as shown in Figure 1. These regions are Northeastern (NE) region, including Liaoning, Jilin, and Heilongjiang, Northern Coastal (NC) region, including, Beijing, Tianjin, Hebei, and Shandong, Eastern Coastal (EC) region, including Shanghai, Jiangsu, and Zhejiang, Southern Coastal (SC) region, including Guangdong, Fujian, and Hainan, Middle of the Yellow River (HC), including Inner Mongolia, Shanxi, Henan, and Shaanxi, Middle of the Yangtze River (YC), including Hubei, Hunan, Jiangxi, and Anhui, Southwest (SW) region, including Chongqing, Sichuan, Yunnan, Guizhou, and Guangxi, and Northwest (NW) region, including Gansu, Qinghai, Ningxia, Tibet, and Xinjiang. In addition, the sectors are united into 30 industries, the sectoral classifications of which can be seen in S2. 


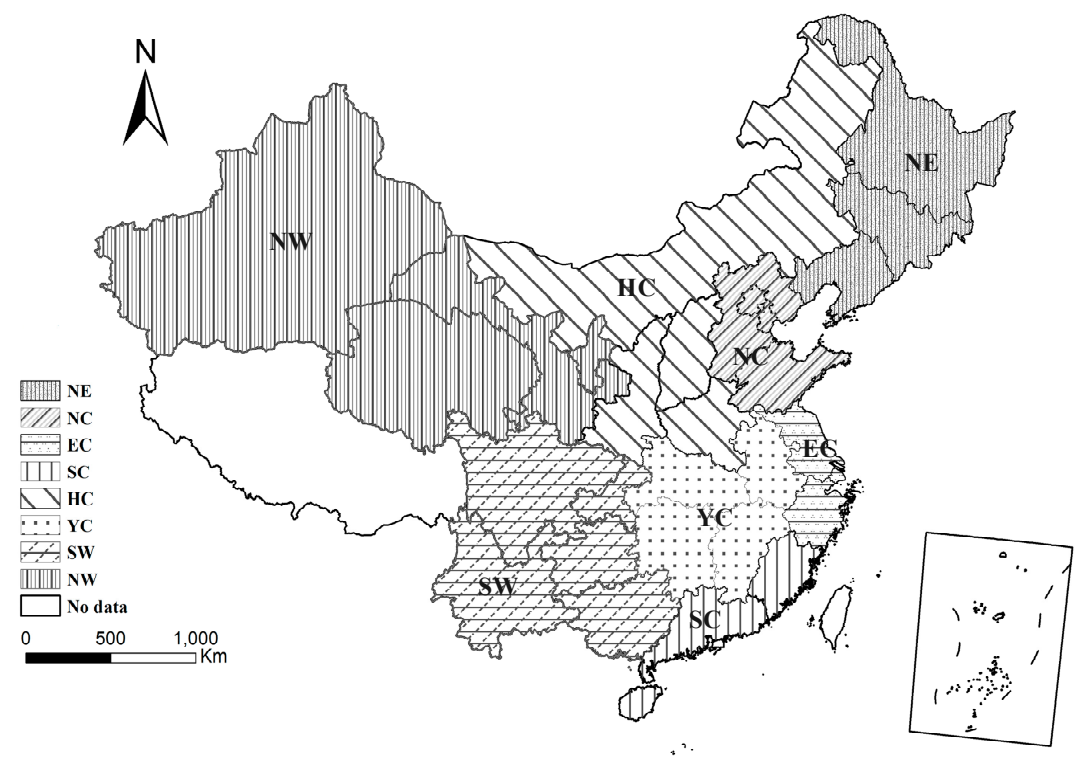

Figure 1. Eight regions of China.

\section{Results and Discussions}

\subsection{Regional Carbon Emissions and Employment Amount}

Figure 2 provides an overall view of China's regional carbon emissions and employment changes during 2007-2012. Carbon emission in NW grew by $88.3 \%$ in five years, followed by SW (49.0\%) and $\mathrm{HC}(48.1 \%)$, and the least was in EC with only $25.9 \%$. In terms of employment, EC had a growth rate of $41.5 \%$, followed in order by SC (32.9\%) and HC (29.8\%), while NE had the lowest growth rate of $7.6 \%$. It is clear that carbon emission grew faster than employment in NW, HC, NE, SW, and YC, and the opposite occurred in EC, which had the highest GDP per capita. The figure indicates that the growth of carbon emission and employment was not synchronous in each region.

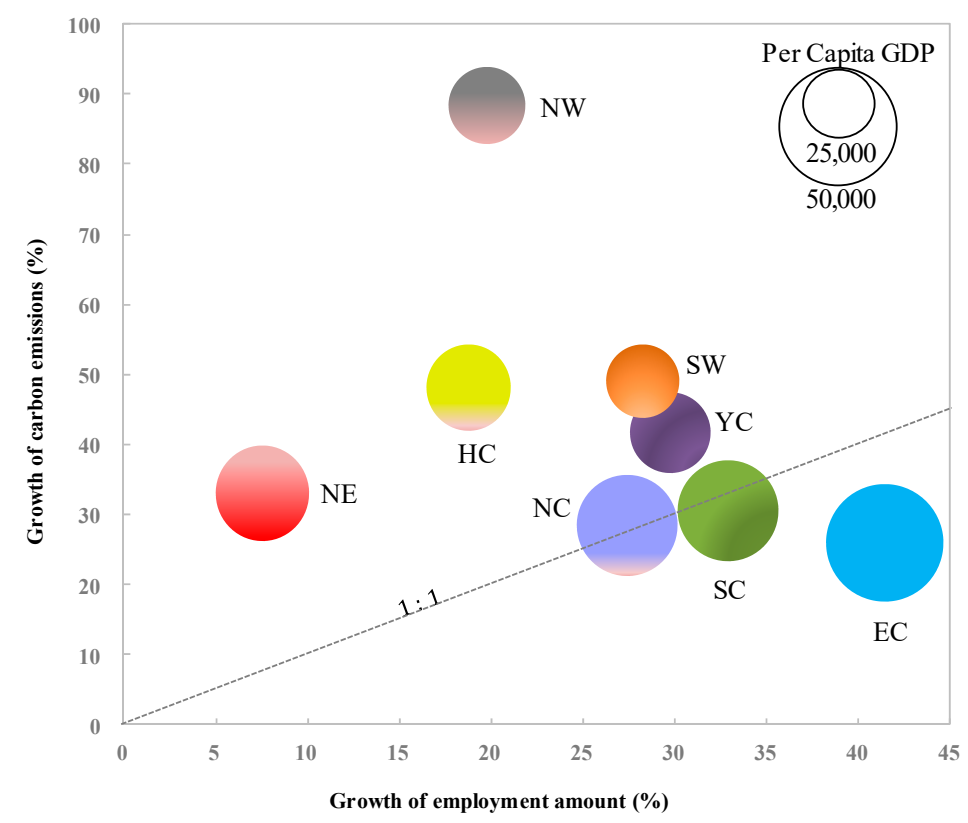

Figure 2. Growth rates of regional carbon emissions and employment amount during 2007-2012. Note: The unit of per capita GDP is the RMB Yuan, and the value is calculated in 2012 prices (1 RMB Yuan $=0.1593$ USD in 2012). 
Sectoral share of carbon emissions and employment is shown in Figure 3. NC and HC had the largest carbon emissions in the country, which surpassed 1.7 billion tons in 2012, and NC and EC had the largest numbers of employment. The sectoral share of carbon emissions in regions differed from that of employment. Electricity and gas supply was the first source of carbon emissions in all regions, accounting for $36 \%$ to $60 \%$, followed by raw material manufacturing, accounting for $19 \%$ to $34 \%$. On the other hand, other services were the heaviest employment department in all regions, accounting for $38 \%$ to $54 \%$, followed by construction and equipment manufacturing. It can be concluded that the sectoral share of carbon emissions was widely divergent from that of employment in regions.



(a) Carbon emissions

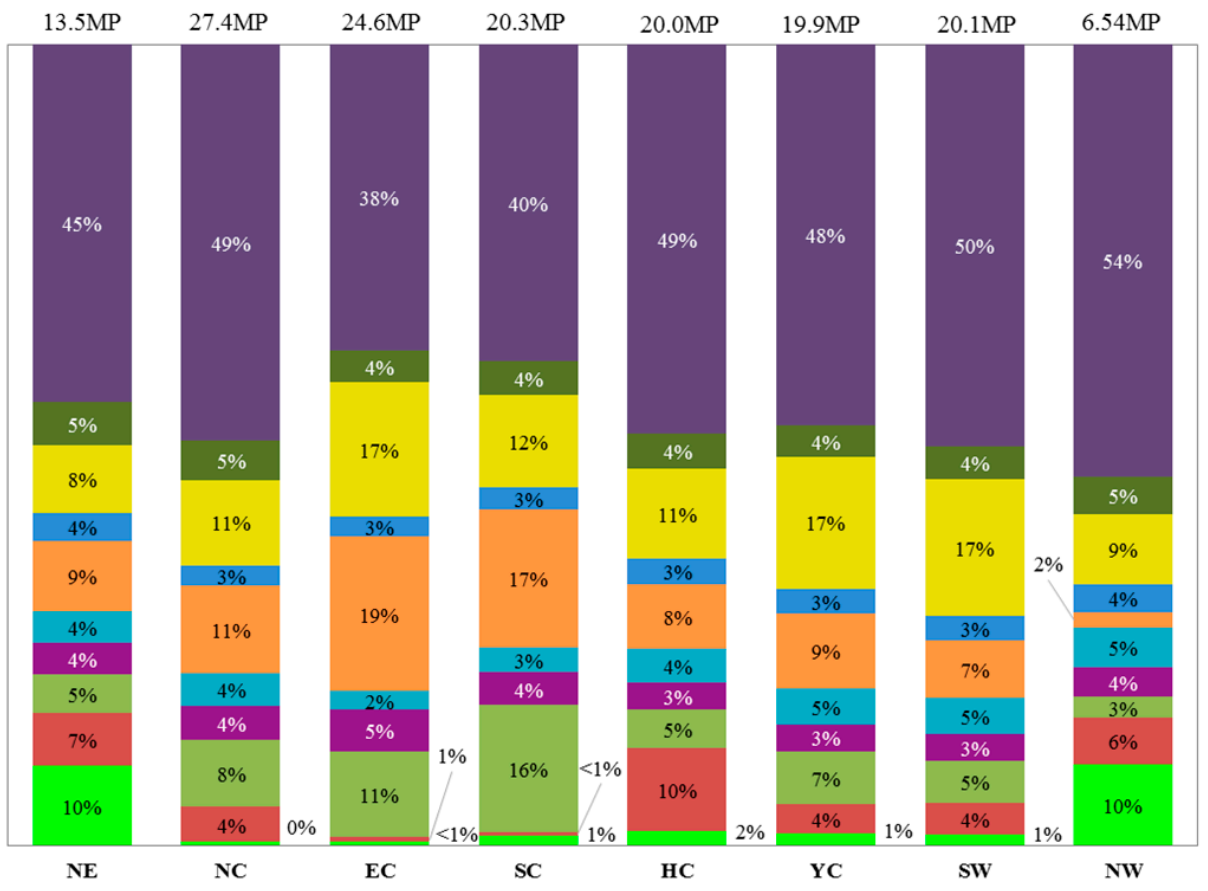

(b) Employment

Figure 3. Cont. 

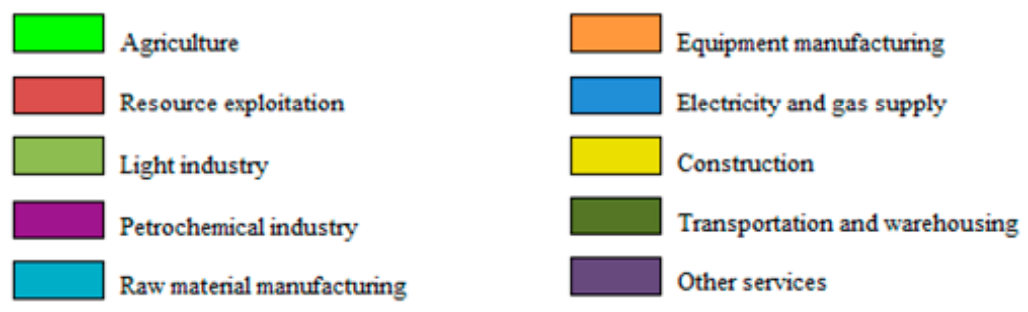

Figure 3. Sectoral share of carbon emissions and employment in 2012. Note: The units of carbon emissions: MT (million tons) and BT (billion tons), and the unit of employment: MP (million employed population).

\subsection{Results of Structural Decomposition}

There was a $38.9 \%$ increase in carbon emission and a $26.9 \%$ increase in total employment during 2007-2012 in China. Changes in regional emissions and employment amounts are decomposed into various effects by MRIO-based SDA, including intensity effect (Ine), production technology effect (Pte), domestic final demand scale effect (Fds), domestic final demand preference effect (Fdp), domestic final demand structure effect (Fse), export scale effect (Ese), and export preference effect (Epe). The results are shown in Figure 4. According to the decomposition results of carbon emissions, Fds was the dominant driving force of regional carbon emissions growth in all regions, while Ine was the dominant driving force of reducing carbon emissions. Pte played a suppressing role on carbon emissions in NE, $\mathrm{EC}$ and SC but a boosting role in other regions.

For regional employment amounts changes, the two factors of Fds and Ine dominated in promoting and restraining respectively, while Pte was a significant factor promoting employment in all regions except in NW. Other factors, such as Fse, Fdp, Epe, and Ese, played less important roles.

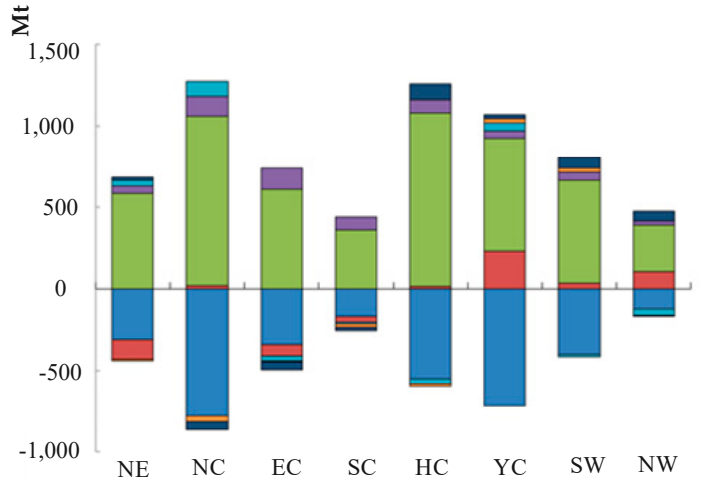

(a) Carbon emissions

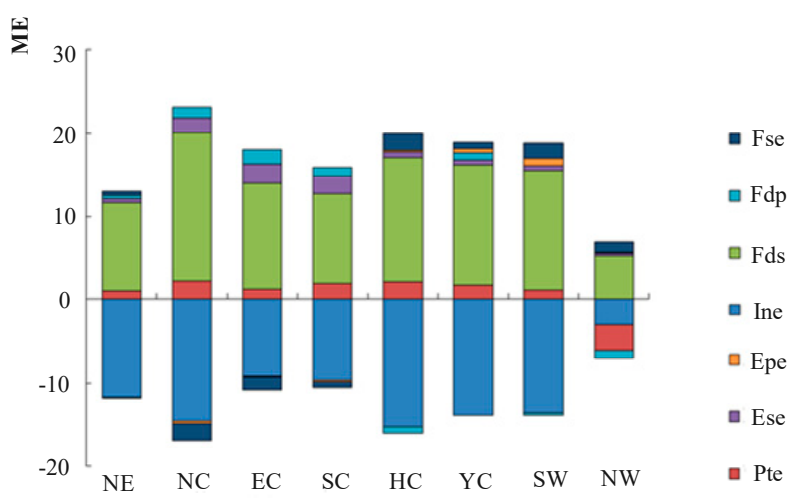

(b) Employment amount

Figure 4. Decomposition results of regional carbon emissions and employment amount. Note: The units MT and MP in the figure represent one million tons and one million employees, respectively.

\subsection{Spillover of Carbon Emissions and Employment}

After analyzing factors of changes in regional carbon emissions and employment amount, we attempt to investigate the bilateral relationships of spillover effects in determining changes in regional emissions and employment. Changes in a region's final demand can affect its emission and employment growth through intra-regional supply chains and can also affect other regions through inter-regional supply chains. As shown in S3, Figure S1 divides all the effects into own influences and spillover effects due to different factors in different regions. Figure S2 in S4 shows bilateral regional spillover effects caused by different factors, such as changes of technology, final demand scale, final demand preference, final demand structure, export scale, and export preference. 
The first factor Pte was conductive to reducing carbon emissions and employment amounts in all regions, but it contributed much more to own influence than spillover. The impacts on the carbon emissions varied in different regions. It is obvious that the Pte in EC and SC helped to reduce carbon emissions in all regions. In contrast, Pte in YC, SW and NW increased the carbon emissions in most regions. Pte's spillover effects promoted employment in most regions, as supply chain cooperation in various regions was increasingly strengthening and had created several new jobs. However, Pte failed to promote employment in NW.

Fds played a dominant role in increasing carbon emissions and employment amounts in all region. Fds drove employment amounts growth in all regions due to own influences, much more than spillover effects, because most of the final demand in a region was normally fulfilled by internally products produced by local employees. Fdp can affect local or other regions' carbon emissions through domestic supply chains, which varied greatly in different regions. It needs to be noted that Fdp reduced carbon emissions and employment amounts in NC, EC and SC by spillover effects, and in NW by its own influence. Fse refers to the changes in consumption structure and investment structure. Fse decreased carbon emissions in the three coastal regions (NC, EC and SC) and increased in others. So as the effects on employment. The bilateral relationship shows that the Fse from all regions reduced employment amounts in coastal regions but contributed to increasing employment amounts in other regions. This outcome can be partly attributed to the transition in the final demand structure (including consumption and investment) in the coastal regions, which resulted in growth of emissions and employment amounts in other regions.

The change of export amount (Ese) contributed to carbon emissions and employment amounts growth in coastal regions dramatically. The own influences and spillovers effects of Ese on the coastal regions were much stronger than those on interior regions, which indicated that the role of coastal regions in China's export was promoted. However, the change of export preference (Epe) presented different results, which decreased carbon emissions and employment amounts in the coastal regions due to export adjustment. In addition, Epe increased carbon emissions and employment amounts in most interior regions, indicating that interior regions were affected reversely compared with the coastal regions.

In summary, technology change was conductive to reducing carbon emissions and employment amounts in all regions, while other factors shew diversity of spillover effects on regional carbon emissions and employment amounts. All of the spillover effects demonstrated that inter-regional and international trade in China were in transition.

\subsection{Spillover Effects on Regional ICE}

It is difficult for individual regions to make trade-off decisions to promote employment or abate carbon emissions due to spillover effects. To clarify the spillover effects on individual regions in detail, the effects on ICE of the destination regions are considered. The comparisons of local ICE and spilled ICE in eight regions are shown in Figure 5. The blue line is the benchmark of local ICE, and the points on the benchmark represent local ICE of eight regions in 2007. Other points represent spilled ICE due to different factors, which are located around the benchmark. Compared with the benchmark, the spillover effect is negative if the point is higher than the benchmark because the spillover effect will enhance the ICE of the region. Otherwise, more analysis is required to confirm the direction of effect, as introduced in Equation (2). Distinctively, the points with the abscissa values less than zero need to be proved to reduce or increase ICE of the corresponding regions. The results of comparisons indicate that the spillover effects of factors on regional ICE are apparently different. For example, the spilled ICE of Pte in most regions is lower than the benchmark, while that of Ese in some regions is higher than the benchmark. 


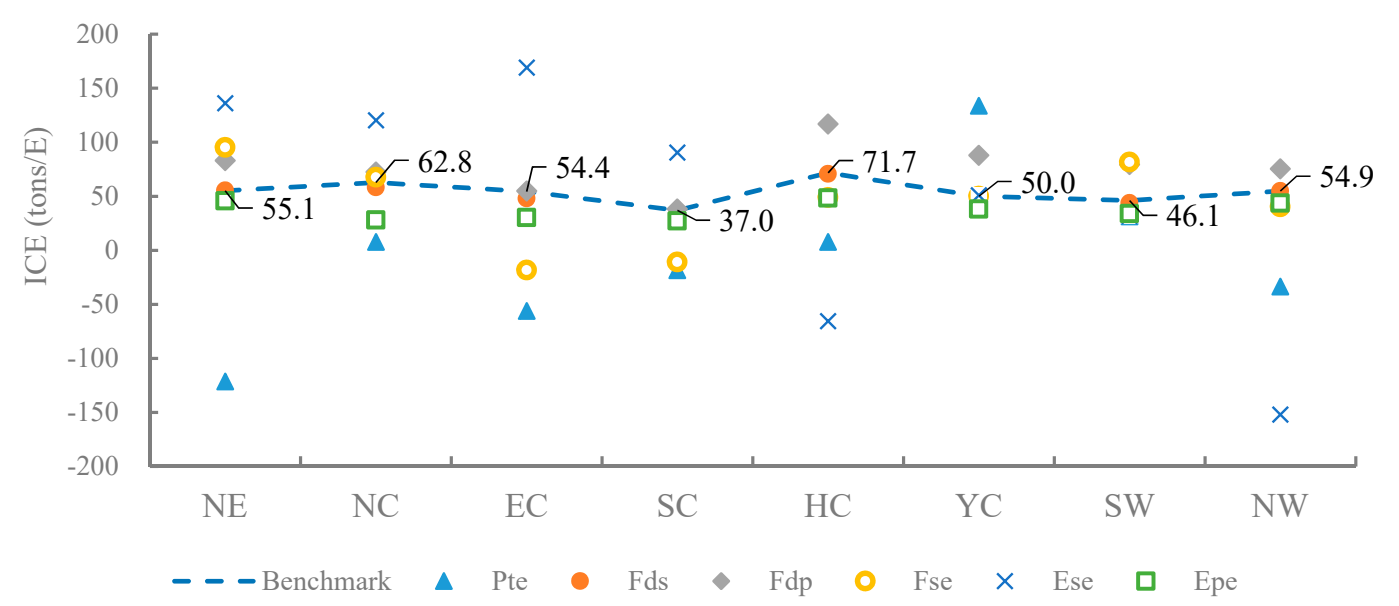

Figure 5. Local ICE benchmark and spilled ICEs of factors.

Furthermore, indices $P I I^{s \rightarrow o t h e r s}$ and $P I I^{o t h e r s \rightarrow s}$ of regions are calculated based on Equation (3) and Equation (4), and the results are shown in S5. The former indicates the positive spillover effects of region $s$ on other regions, and the latter indicates the positive spillover effects of other regions on region s. According to the results of PIIs, each region tended to shift carbon emission outward and leave employment. The results are combined and transformed into a checkerboard diagram as illustrated in Figure 6. The figure reveals the bilateral spillover relationships between regions and the own influences on regional ICE. The green circle indicates positive effect of the spillover effect from the left region to the upper region, while the hollow circle indicates negative effect. The right and below sides are proportions of regions with positive effects or negative effects in all regions, which is calculated according to regional GDP. As spillover effects are comprehensive, governments should not blindly support employment spillover, or oppose carbon emission spillover. Instead, it is reasonable to reduce the carbon emission per employee in the process of spillover. Therefore, studying on spillover effects on regional ICE will make greater contribution to spillover regulation. From the results in Figure 6, the spillover effects on regional ICE were mostly negative, especially those from YC, SW, and NW. Only SC and EC had more positive effects than negative ones on other regions. From the perspective of the spillover-accepted regions, NC, YC, and HC were relatively dominant in positive effects. Other regions were mainly affected by negative spillovers, such as SC. In contrast, all of the regions had positive impacts on themselves except NW. It can be seen that most of the spillover effects between regions in China were not conducive to improving the carbon efficiency of the destination regions. In other words, positive inter-regional cooperative relations on ICE were rare in China during the period. 


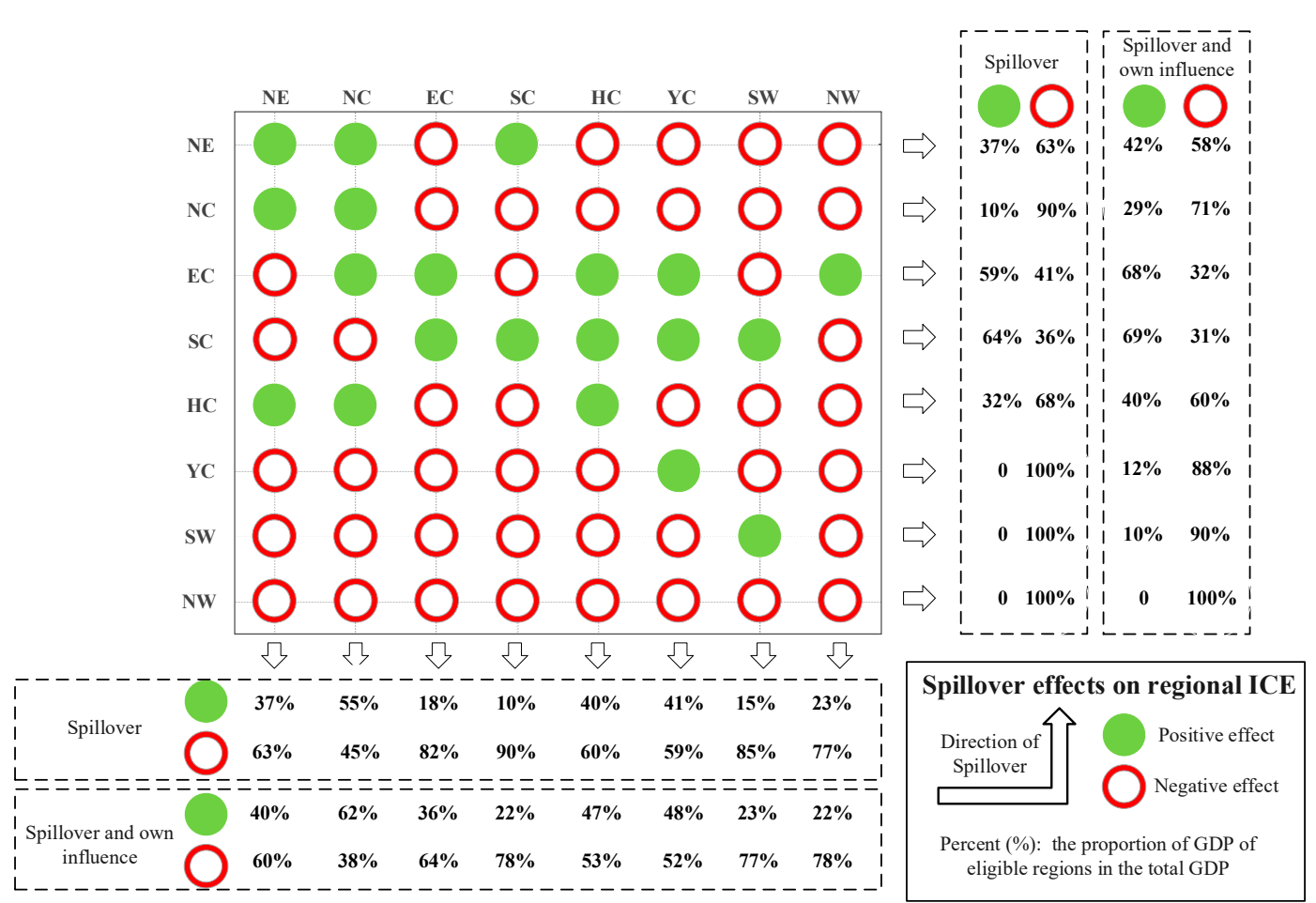

Figure 6. Spillover effects on regional ICE.

In general, the spillovers from coastal regions (EC and SC) to others tended to have positive effects on ICE, while the spillovers from the interior regions (YC, SW and NW) to others tended to have negative ones. The spillovers from other regions to NW and SW were basically negative. The spillover effects that can truly decrease ICE were relatively rare, and the regions with positive effects were far fewer than those with negative effects. Industrial transfer, changes in demand structure and strengthening of inter-regional linkages were key factors of the direction of spillover effects.

Combined with the value of PIIs, technology improvement, change in final demand and export preference had the potential to reduce ICE through spillover effects. To achieve more balanced development in China, the spillover caused by Pte, Epe and Fse to the interior regions should be promoted so that the growth rate of employment amount could be higher than those of carbon emissions.

\subsection{Discussion and Policy Implications}

\subsubsection{Discussion}

Carbon emission reduction and employment growth in a region depending not only on their own efforts but also on possible spillover effects, have very important policy implications. The spillover effect on regional ICE, which is judged as positive or negative, can reveal inter-regional interactions and enlighten spillover regulation. Figure 7 is a schematic diagram of spillover effects and corresponding regulation targets. It is worth noting that not only carbon emission and employment but also pollutant emissions, value added, and taxation are important indicators that should be concerned with in the study of spillover effects. 


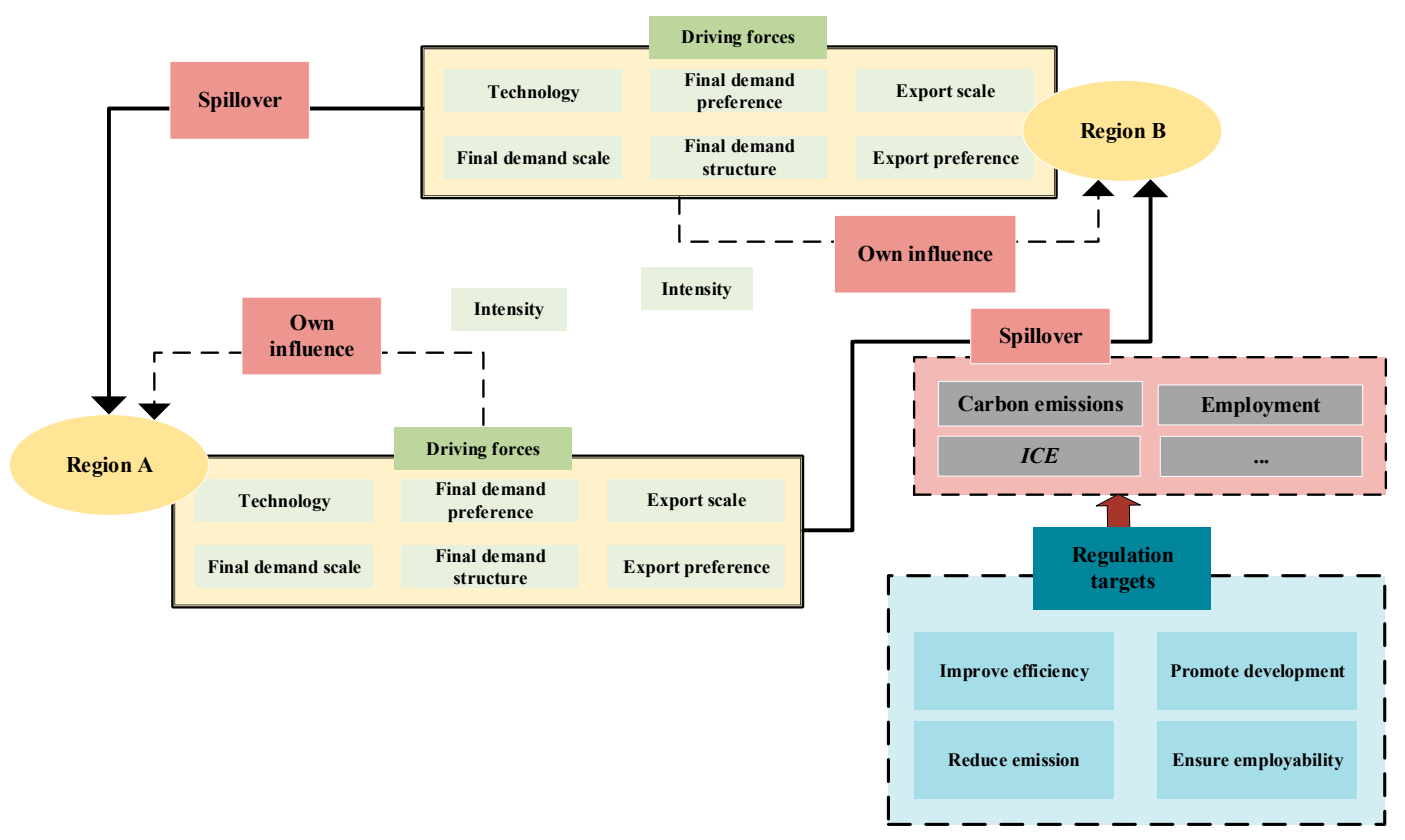

Figure 7. Schematic diagram of spillover effects and regulation targets.

In China, inter-regional spillover is not be dominated by a single region, but by all of the involved regions and even other countries. Thus multi-regional cooperation are significant for spillover regulation. As a matter of fact, China has made progress on the objective. The targets of regional policies have transformed from single region development to inter-regional and international cooperation promotion. The former includes the special economic zones established at the beginning of reform and opening up, and the national-level new districts, and the latter includes the Belt and Road initiative, the Beijing-Tianjin-Hebei coordinated development zone and the Yangtze River Economic Belt, proposed recently. The new kinds of strategies and policies will result in a win-win situation by promoting large-scale regional economic integration.

In addition, spillover of emissions, employment and economic benefits, as well as the hidden factors, should be taken into account. For example, the increasing trade of intermediate goods will increase carbon emissions in underdeveloped regions. However, it is also a driver of increasing employment amount due to industrialization. In summary, these phenomena and relevant policies are closely related to inter-regional spillover effects, which require more in-depth studies.

\subsubsection{Policy Implications}

As shown in Figure 7, various factors are the fundamental drivers of spillover, and adjustment of these driving forces will be beneficial to optimizing spillover effects, especially for underdeveloped regions. According to the results of spillover effects analysis, regulation measures can be implemented by governments in initiative regions or destination regions, or in both regions. The targets may include efficiency improvement, economic structure optimization, emissions reduction and employability stability. Specifically, the policies can be designed to promote technology transfer (including non-fossil energy development), supply chain cooperation, industrial transfer, and improve environmental regulation in underdeveloped regions.

From the results of spillover estimation and structural decomposition analysis, policies can be made to reinforce the driving forces of positive spillover effects. For example, to promote employment and reduce carbon emissions simultaneously in interior regions, the final demand preference effect of coastal regions should be considered. Making full use of technological effects to interior regions can effectively reduce carbon emissions in coastal regions and have little impact on employment. It is necessary to actively promote the transition of final demand and exports in all regions. The country 
can actualize this goal by promoting consumption transition in interior regions and expanding exports of service industry. These measures can bring not only about upgrading of employment structure but can also inhibit carbon emissions growth to some extent. The proportion of employment amount in the service industry in China is far lower than that in developed countries. For interior regions, consumption transition to service industry could expand job opportunities and avoid employment shifting to coastal regions. For coastal regions, expanding exports of service industry is also important to create high-level jobs and decrease ICE in most regions.

\section{Conclusions}

Overall, the evolution of inter-regional spillover of carbon emissions and employment from 2007 to 2012 were analyzed based on SDA method and MRIO tables in this paper. Specifically, we focused on the bilateral spillover effects in eight major regions of China.

From 2007 to 2012, carbon emissions and employment amounts of China's regions grew rapidly at the same time. For the eight regions, the final demand scale change was the dominant factor of carbon emissions and employment growth, while the intensity change was the dominant factor of carbon emissions and employment amount reduction. Other factors shew diversity of contributions to carbon emissions and employment growth.

Spillover effects rarely reduced the ICE of regions, but the own influences can decrease it in most regions. Although spillover may contribute to economic development in most regions, it was hardly a driver of efficiency improvement for destination regions. Positive inter-regional cooperative relations on ICE were rare in China against the background of carbon emissions control and economic transition, as negative spillover effects dominated. To strengthen positive spillover effects on underdeveloped regions, the contributions of export preference change, final demand structure change, and technological improvement should be promoted.

The contributions of this study refer to examining of spillover effects not only on carbon emissions and employment, but also on efficiency indicator ICE, so that the perspective of spillover effects can be shifted from quantity to efficiency. By distinguishing spillover effects to positive and negative ones, this study enhances the comprehensiveness and dialecticality of inter-regional spillover. The limitations of this study include that the conclusion comes from a short period of 5 years due to constraints of data. Even it was from Chinese official website, the classification of 30 provinces into eight regions may affect the results of spillover effect analysis, as it will present different results if we choose another approaches.

Here are some suggestions for follow-up research. Comprehensive spillover effects and those in 30 provinces in China can be further studied systematically. The development tendency and policies behind driving forces need to be analyzed to better explore the relationship between driving forces and policies, thus corresponding policy suggestions can be put forward. Finally, the spillover effects between China and other countries are as important as, or even more significant than, domestic spillover, against the background of globalization and further opening up of China's economy. Global input-output tables will be needed to study the spillover effects in different countries.

Supplementary Materials: The following are available online at http://www.mdpi.com/2071-1050/11/13/3622/s1, S1: MRIO-based SDA, S2: Classification of production sectors, S3: Own influences and spillover effects by region, S4: Spillover effects analysis based on results of SDA, S5: Positive contribution of spillover effects, Table S1: Classification of production sectors, Figure S1: Own influences and spillover effects, Figure S2: Bilateral spillover effects, Figure S3: Regions' positive spillover effects on other regions, Figure S4: Regions with positive spillover effects from other regions.

Author Contributions: Conceptualization, F.L., Y.B. and S.Y.; methodology, F.L. and Z.Y.; software, Z.Y. and W.S.; validation, F.L. and W.X.; formal analysis, F.L. and W.S.; investigation, F.L.; resources, F.L. and Z.T.; data curation, Z.T.; writing-original draft preparation, W.S.; writing-review and editing, F.L.; visualization, W.S.; supervision, F.L.; project administration, F.L. and W.X.; funding acquisition, F.L. and Z.T.

Funding: This research was funded by National Natural Science Foundation of China $(41401126,41771135)$.

Conflicts of Interest: The authors declare no conflict of interest. 


\section{References}

1. United Nations Environment Programme. UN Environment 2018 Annual Report. Available online: https://www.unenvironment.org/annualreport/2018/index.php (accessed on 5 May 2019).

2. Dong, L.; Liang, H. Spatial analysis on China's regional air pollutants and $\mathrm{CO}_{2}$ emissions: Emission pattern and regional disparity. Atmos. Environ. 2014, 92, 280-291. [CrossRef]

3. Xie, X.; Cai, W.; Jiang, Y.; Zeng, W. Carbon Footprints and Embodied Carbon Flows Analysis for China's Eight Regions: A New Perspective for Mitigation Solutions. Sustainability 2015, 7, 10098-10114. [CrossRef]

4. Deng, G.; Ding, Y.; Ren, S. The study on the air pollutants embodied in goods for consumption and trade in China-Accounting and structural decomposition analysis. J. Clean. Prod. 2016, 135, 332-341. [CrossRef]

5. Wu, L.; Zhong, Z.; Liu, C.; Wang, Z. Examining PM2.5 Emissions Embodied in China's Supply Chain Using a Multiregional Input-Output Analysis. Sustainability 2017, 9, 727. [CrossRef]

6. Huang, M.; Chen, Y.; Zhang, Y. Assessing Carbon Footprint and Inter-Regional Carbon Transfer in China Based on a Multi-Regional Input-Output Model. Sustainability 2018, 10, 4626. [CrossRef]

7. Su, B.; Ang, B. Structural decomposition analysis applied to energy and emissions: Some methodological developments. Energy Econ. 2012, 34, 177-188. [CrossRef]

8. Hoekstra, R.; Michel, B.; Suh, S. The emission cost of international sourcing: Using structural decomposition analysis to calculate the contribution of international sourcing to $\mathrm{CO}_{2}$-emission growth. Econ. Syst. Res. 2016, 28, 151-167. [CrossRef]

9. Xu, S.; Zhang, W.; Li, Q.; Zhao, B.; Wang, S.; Long, R. Decomposition Analysis of the Factors that Influence Energy Related Air Pollutant Emission Changes in China Using the SDA Method. Sustainability 2017, 9, 1742. [CrossRef]

10. Zhang, M.; Huang, X.-J. Effects of industrial restructuring on carbon reduction: An analysis of Jiangsu Province, China. Energy 2012, 44, 515-526. [CrossRef]

11. Pan, W.; Yang, D.; Lin, M. Inter-industry Technology Spillover Effects in China: Evidence from 35 Industrial Sectors. China World Econ. 2012, 20, 23-40. [CrossRef]

12. Chung, W.-S.; Tohno, S.; Shim, S.Y. An estimation of energy and GHG emission intensity caused by energy consumption in Korea: An energy IO approach. Appl. Energy 2009, 86, 1902-1914. [CrossRef]

13. Madariaga, R. Factors driving sectoral and occupational employment changes during the Spanish boom (1995-2005). Econ. Syst. Res. 2018, 30, 400-421. [CrossRef]

14. Wang, H.; Ang, B.; Su, B. A multi-region structural decomposition analysis of global $\mathrm{CO}_{2}$ emission intensity. Ecol. Econ. 2017, 142, 163-176. [CrossRef]

15. Deng, G.; Xu, Y. Accounting and structure decomposition analysis of embodied carbon trade: A global perspective. Energy 2017, 137, 140-151. [CrossRef]

16. Guo, J.E.; Zhang, Z.; Meng, L. China's provincial $\mathrm{CO}_{2}$ emissions embodied in international and interprovincial trade. Energy Policy 2012, 42, 486-497. [CrossRef]

17. Wang, Z.; Xiao, C.; Niu, B.; Deng, L.; Liu, Y. Identify sectors' role on the embedded $\mathrm{CO}_{2}$ transfer networks through China's regional trade. Ecol. Indic. 2017, 80, 114-123. [CrossRef]

18. Feng, K.; Davis, S.J.; Sun, L.; Li, X.; Guan, D.; Liu, W.; Liu, Z.; Hubacek, K. Outsourcing $\mathrm{CO}_{2}$ within China. Proc. Natl. Acad. Sci. USA 2013, 110, 11654-11659. [CrossRef]

19. Liu, H.; Liu, W.; Fan, X.; Zou, W. Carbon emissions embodied in demand-supply chains in China. Energy Econ. 2015, 50, 294-305. [CrossRef]

20. Mi, Z.; Guan, D.; Meng, J.; Hubacek, K.; Song, M.; Wei, Y.-M.; Shan, Y.; Liu, Z. Chinese $\mathrm{CO}_{2}$ emission flows have reversed since the global financial crisis. Nat. Commun. 2017, 8, 1712. [CrossRef]

21. Yang, L.; Lahr, M.L. The Drivers of China's Regional Carbon Emission Change-A Structural Decomposition Analysis from 1997 to 2007. Sustainability 2019, 11, 3254. [CrossRef]

22. Roncolato, L.; Kucera, D. Structural drivers of productivity and employment growth: A decomposition analysis for 81 countries. Camb. J. Econ. 2013, 38, 399-424. [CrossRef]

23. Hudcovský, M.; Lábaj, M.; Morvay, K. Employment Growth and Labour Elasticity in V4 Countries: Structural Decomposition Analysis. Prague Econ. Pap. 2017, 2017, 422-437. [CrossRef]

24. Zhao, Y.; Wang, S.; Liu, Y.; Zhang, Z.; Zhang, Y.; Li, H. Identifying the economic and environmental impacts of China's trade in intermediates within the Asia-Pacific region. J. Clean. Prod. 2017, 149, 164-179. [CrossRef] 
25. Tang, X.; McLellan, B.C.; Zhang, B.; Snowden, S.; Höök, M. Trade-off analysis between embodied energy exports and employment creation in China. J. Clean. Prod. 2016, 134, 310-319. [CrossRef]

26. Mayer, J. Global rebalancing: Effects on trade and employment. J. Asian Econ. 2012, 23, 627-642. [CrossRef]

27. Chen, L.; Yang, Z. A spatio-temporal decomposition analysis of energy-related $\mathrm{CO}_{2}$ emission growth in China. J. Clean. Prod. 2015, 103, 49-60. [CrossRef]

28. Zhong, Z.; Jiang, L.; Zhou, P. Transnational transfer of carbon emissions embodied in trade: Characteristics and determinants from a spatial perspective. Energy 2018, 147, 858-875. [CrossRef]

29. Meng, B.; Xue, J.; Feng, K.; Guan, D.; Fu, X. China's inter-regional spillover of carbon emissions and domestic supply chains. Energy Policy 2013, 61, 1305-1321. [CrossRef]

30. Meng, B.; Wang, J.; Andrew, R.; Xiao, H.; Xue, J.; Peters, G.P. Spatial spillover effects in determining China's regional $\mathrm{CO}_{2}$ emissions growth: 2007-2010. Energy Econ. 2017, 63, 161-173. [CrossRef]

31. Liu, W.; Chen, J.; Tang, Z.; Liu, W.; Han, D.; Li, F. The 2007 China Multi-Region Input-Output Table of 30 Provincial Units; China Statistics Press: Beijing, China, 2012.

32. Liu, W.; Tang, Z.; Han, M. The 2012 China Multi-Region Input-Output Table of 31 Provincial Units; China Statistics Press: Beijing, China, 2018.

33. Liu, W.; Li, X.; Liu, H.; Tang, Z.; Guan, D. Estimating inter-regional trade flows in China: A sector-specific statistical model. J. Geogr. Sci. 2015, 25, 1247-1263. [CrossRef]

34. China Emission Accounts and Datasets. Provincial-Level $\mathrm{CO}_{2}$ emission inventory (by IPCC Sectoral Approach). Available online: http://www.ceads.net/data/inventory-by-sectoral-approach/ (accessed on 5 February 2019).

35. National Bureau of Statistics of China. China Population and Employment Statistics Yearbook 2008; China Statistics Press: Beijing, China, 2008.

36. National Bureau of Statistics of China. China Population and Employment Statistics Yearbook 2013; China Statistics Press: Beijing, China, 2013.

37. National Bureau of Statistics of China. China Statistics Yearbook 2013; China Statistics Press: Beijing, China, 2013.

38. Development Research Center of the State Council of China. Carbon Emission Reduction in China's Eight Comprehensive Economic Zones: Type Zoning and Policy Recommendations. Available online: http://www.drc.gov.cn/xsyzcfx/20141017/4-4-2884606.htm (accessed on 5 February 2019).

(C) 2019 by the authors. Licensee MDPI, Basel, Switzerland. This article is an open access article distributed under the terms and conditions of the Creative Commons Attribution (CC BY) license (http://creativecommons.org/licenses/by/4.0/). 